University of Nebraska - Lincoln

DigitalCommons@University of Nebraska - Lincoln

6-2011

Detecting Spatiotemporal Changes of Corn Developmental Stages in the U.S. Corn Belt Using MODIS WDRVI Data

Toshihiro Sakamoto

Brian D. Wardlow

University of Nebraska-Lincoln, bwardlow2@unl.edu

Anatoly A. Gitelson

University of Nebraska-Lincoln, agitelson2@unl.edu

Follow this and additional works at: https://digitalcommons.unl.edu/natrespapers

Part of the Natural Resources and Conservation Commons

Sakamoto, Toshihiro; Wardlow, Brian D.; and Gitelson, Anatoly A., "Detecting Spatiotemporal Changes of Corn Developmental Stages in the U.S. Corn Belt Using MODIS WDRVI Data" (2011). Papers in Natural Resources. 352.

https://digitalcommons.unl.edu/natrespapers/352

This Article is brought to you for free and open access by the Natural Resources, School of at DigitalCommons@University of Nebraska - Lincoln. It has been accepted for inclusion in Papers in Natural Resources by an authorized administrator of DigitalCommons@University of Nebraska - Lincoln. 


\title{
Detecting Spatiotemporal Changes of Corn Developmental Stages in the U.S. Corn Belt Using MODIS WDRVI Data
}

\author{
Toshihiro Sakamoto, Brian D. Wardlow, and Anatoly A. Gitelson
}

\begin{abstract}
The dates of crop developmental stages are important variables for many applications including assessment of the impact of abnormal weather on crop yield. Time-series 250-m vegetation-index (VI) data acquired from the Moderate Resolution Imaging Spectroradiometer (MODIS) provide valuable information for monitoring the spatiotemporal changes of corn growth across large geographic areas. The goal of this study is to evaluate the performance of a new crop phenology detection method, namely, two-step filtering (TSF), for revealing the spatiotemporal pattern of specific corn developmental stages (early vegetative: V2.5; silking: R1; dent: R5; mature: R6) over an eight-year period (2001-2008) across Iowa, Illinois, and Indiana using MODISderived Wide Dynamic Range VI data. Weekly crop progress reports produced by the U.S. Department of Agriculture National Agricultural Statistics Service (NASS) were used to assess the accuracy of TSF-based estimates of corn developmental stages. The results showed that the corn developmental stages could be estimated with high accuracy (the root mean squared error ranged from 4.1 to 5.5 days, the determination coefficient ranged from 0.66 to 0.84 , and the coefficient of variation ranged from $2.1 \%$ to $3.7 \%$ ) based on NASS-derived statistics on an agricultural statistics district level. In particular, the annual changes in the spatiotemporal patterns of the estimated silking stage had a high level of agreement with those of the NASS-derived statistics. These results suggested that the TSF method could provide local-scale information of corn phenological stages, which had an advantage over the NASS-derived statistics particularly in terms of the spatial resolution.
\end{abstract}

Index Terms-Agriculture, optical imaging, remote sensing, time series, vegetation mapping.

\section{INTRODUCTION}

$\mathbf{T}$ HE U.S. Corn Belt, which comprises several midwestern states, is one of the world's largest corn production regions and represents a major source of grain that is exported from the U.S. The majority of corn in this region is grown under rain-fed conditions. Considering that a crop's physiological response (e.g., light-use efficiency, sterility, or transpiration rate) to extreme weather conditions varies depending on crop

Manuscript received May 4, 2010; revised August 6, 2010; accepted November 16, 2010. Date of publication January 5, 2011; date of current version May 20, 2011. This work was supported by the Japanese Society for the Promotion of Science (JSPS) under the JSPS Postdoctoral Fellowships for Research Abroad.

T. Sakamoto is with the School of Natural Resources, University of Nebraska-Lincoln, Lincoln, NE 68588 USA, and also with the Ecosystem Informatics Division, National Institute for Agro-Environmental Sciences, Tsukuba 305-8604, Japan (e-mail: sakamt@affrc.go.jp).

B. D. Wardlow and A. A. Gitelson are with the School of Natural Resources, University of Nebraska-Lincoln, Lincoln, NE 68588 USA.

Digital Object Identifier 10.1109/TGRS.2010.2095462 developmental stages, annual corn production can be associated with the spatiotemporal relationship between abnormal weather conditions (e.g., flood, drought, or hail) and specific crop developmental stages (e.g., early vegetative stage, flowering stage, or mature stage) on a regional scale. Moreover, deficient or excessive soil-moisture conditions and soil temperature in the spring result in variable corn planting dates across large geographic areas, as well as influence other crop management decisions. Although weather conditions are well monitored by weather station networks on a real-time basis, the practical method that enables the spatiotemporal pattern of crop developmental stages to be revealed has not been well established in the U.S. Reliable archival records related to crop developmental stages have been regularly recorded by the U.S. Department of Agriculture (USDA) National Agricultural Statistics Service in crop progress reports (CPRs) (NASS-CPRs; reports are publicly available at http://www.nass.usda.gov/). However, NASS-CPR records the progress of crop developmental stages by the percent complete (area ratio) over a large administrative unit. The geographic reporting unit, which is the entire state or agricultural statistics district (ASD; a substate region comprised of multiple counties), is too large to reveal detailed spatial patterns of crop developmental stages. It has been difficult to assess the effect of local weather-condition changes on crop productivity with particular reference to the spatiotemporal pattern of crop phenology. Thus, remote-sensing techniques are expected to present a reasonable solution to characterize localscale annual changes in crop developmental stages over large regions such as the U.S. Corn Belt.

Time-series vegetation-index (VI) data, which are obtained by the Advanced Very High Resolution Radiometer or Moderate Resolution Imaging Spectroradiometer (MODIS), are commonly used for acquiring phenological information about natural vegetation or agricultural crops across large geographic areas [1]-[12]. The majority of existing phenology detection methods detect specific phenological stages in reference to local features in the time-series VI data based on prescribed thresholds [2], [3], [7], [13]-[16], logistic curve fitting [4], [8], [17]-[19], forward and backward lag periods of smoothed VI data (delayed moving average) [1], [20], [21], or metrics such as maximum, minimum, and inflection points [5], [22]-[24]. Several studies estimate key phenological stages using a combination of time-series VI data and environmental information such as humidity and temperature [6], [25], [26]. The smoothed MODIS VI profile has been effectively used to 
produce agricultural land-use maps [27]-[31] and monitor characteristics of crop phenology [16], [22], [32]-[34] and cropping schedules at a regional scale with moderate resolution imagery (e.g., 250-500 m) [35]. Although these various approaches using time-series VI data have demonstrated the capability to characterize spatiotemporal patterns of vegetation phenology, few of these studies quantitatively evaluated the accuracy of the results to capture the spatial variability and interannual changes that occur in crop phenology across large geographic areas. In addition, most of these studies have estimated phenological stages defined by specific VI metrics (e.g., onset of greenness and senescence), which do not always correspond to specific crop developmental stages defined in crop science (e.g., emergence and mature stage). The phenology detection method based on specific VI metrics (e.g., greenness onset) is potentially affected by extensive weed cover growing before crop planting [4]. Atmospheric conditions and moderate resolution imagery with many mixed pixels (composite spectral-temporal signal from multiple land-cover types) can also produce subtle non-vegetation-related local features in the temporal VI profile that can lead to errors in detecting the key phenological stages with specific metrics (e.g., maximum point [36]) and reduce the estimation accuracy for tracking yearly changes of crop developmental stages.

A new approach, the two-step filtering (TSF) method, has been proposed to improve the performance of the MODISderived crop phenology dates [36]. The TSF method includes a simple smoothing procedure based on the wavelet-based filter to reduce noise components from temporal VI data (first step) and a shape-model fitting procedure to estimate the dates of key phenological stages by overcoming the influence of remaining subtle non-vegetation-related local features (second step). The TSF method can estimate the dates of the key phenological stages of corn: early vegetative stage (V2.5), silking stage (R1), dent stage (R5), and mature stage (R6). The estimation accuracy of corn developmental stages at the field scale was relatively high, i.e., early vegetative stage (V2.5): $r m s e=3.7$ days; silking stage: $r m s e=2.9$ days, dent stage: $r m s e=7.0$ days, and mature stage: $r m s e=3.7$ days. It was also verified that the TSF method is effective in revealing the corn phenological stage variations at a regional scale. Regionaverage estimates calculated using the TSF method agreed well with the USDA statistical data for three ASDs in eastern Nebraska (V2.5: $r m s e=4.1$ days; R1: $r m s e=1.6$ days; R5: $r m s e=5.6$ days; R6: $r m s e=3.3$ days). The preliminary defined parameters of the TSF method were based on the specific data collected in the experimental field sites located in eastern Nebraska, but we do not know how well the TSF method can be applied outside of the state. In addition, the ASD-level statistical data used for regional-scale verification in Nebraska were limited to only two years (2001 and 2002). Thus, it is necessary to test the accuracy of the TSF method in evaluation of interannual variations of corn phenological stages across a larger multistate region.

The objectives of this paper are as follows: 1) to apply the TSF method to characterize the spatiotemporal patterns of corn developmental stages across a three-state area of the U.S. Corn Belt (Illinois, Indiana, and Iowa) using time-series MODIS 250-m VI data observed from 2001 to 2008 and 2) to assess the performance of the TSF method for a spatial extrapolation of corn developmental stages on a multistate scale using statistical data derived from the weekly NASS-CPR.

\section{STUdy AREA}

The study area comprised three major corn-producing states (Iowa, Illinois, and Indiana), where the target corn fields spread over $1000 \mathrm{~km}$ in an east-west direction (longitudes: from $84^{\circ} 47^{\prime} 31^{\prime \prime} \mathrm{W}$ to $96^{\circ} 38^{\prime} 45^{\prime \prime} \mathrm{W}$ ) and over $730 \mathrm{~km}$ in a north-south direction (latitudes: from $36^{\circ} 58^{\prime} 21^{\prime \prime} \mathrm{N}$ to $43^{\circ} 30^{\prime} 9^{\prime \prime} \mathrm{N}$ ). The total corn area harvested for grain was 12.2 million ha in the three states in 2008. The total corn production was 131.9 million tons, which accounted for $42.9 \%$ of the total in the U.S. [37].

\section{Data AND Methods}

\section{A. MODIS WDRVI}

A time series of eight-day composite 250- and 500-m MODIS surface reflectance data (MOD09Q and MOD09A1, Collection 5, tiles: h10v04, h10v05, h11v04, and h11v05) from 2001 to 2008 was used. The 500-m resolution blue-reflectance (Band 3) and day of year (DOY) data layers were resampled to 250-m-resolution images using the nearest neighbor method. The blue-reflectance and DOY layers were used for residual cloud cover detection and time-series analysis in the waveletbased filter, respectively. Even though the MODIS eight-day composite product is corrected for atmospheric effect [38] and provides the best surface spectral-reflectance data for each eight-day period selected by the constrained view-angle maximum value composite method [39], the observed multitemporal VI data still contain short-term fluctuations caused by persistent cloud coverage, bidirectional reflectance distribution function effects, and mixed-pixel effects. Any pixel with a blue reflectance greater than 0.2 [31], [33], [40] was defined as the cloud-covered pixel and was treated as a missing observation in a preprocessing scheme of the wavelet-based filter. Then, the multitemporal VI data were smoothed to reduce the noise components through wavelet transformation [33].

Although the TSF method is expected to be applicable to any time-series VI data such as Normalized Difference VI (NDVI [41]) and Enhanced VI [39], Wide Dynamic Range VI (WDRVI) was selected here because of its near-linear relationship with green leaf area index in a wide range of biomass, including the moderate-to-high-biomass growth stages [42][45]. WDRVI was calculated as [42]

$$
W D R V I=\left(\alpha \times \rho_{\mathrm{NIR}}-\rho_{\text {red }}\right) /\left(\alpha \times \rho_{\mathrm{NIR}}+\rho_{\text {red }}\right)
$$

where $\rho_{\text {NIR }}$ and $\rho_{\text {red }}$ are the 250-m MODIS surface reflectance in the near-infrared (NIR: $841-875 \mathrm{~nm}$, Band 2) and red (red: 621-670 nm, Band 1) bands and $\alpha$ is a weighting coefficient $(\alpha=0.2$ was used in this study [43]).

WDRVI can also be obtained from NDVI by [46]

$$
\begin{aligned}
W D R V I=[(\alpha+1) N D V I+(\alpha-1)] \\
/[(\alpha-1) N D V I+(\alpha+1)] .
\end{aligned}
$$




\section{B. USDA/NASS-CDL}

Target corn pixels were selected using NASS Cropland Data Layer (NASS-CDL), which classifies the spatial distribution of specific crop types on annual basis for selected states. The original NASS-CDL data were resampled from an original spatial resolution of $30 \mathrm{~m}$ (Landsat-based products) $/ 56 \mathrm{~m}$ (Advanced Wide Field Sensor-based products) to $250 \mathrm{~m}$ to match the MODIS data. The percentage area of corn present was then calculated in each 250-m pixel across the three states of the study area where the TSF method was applied only on pixels containing $75 \%$ or more corn. The area threshold (more than or equal to $75 \%$ ) was arbitrarily determined by testing several thresholds and evaluating the spatial distribution of the corn pixels that met that threshold across the study area. The $75 \%$ threshold was selected because it provided a large sample of corn pixels across the three states while ensuring that corn was the dominant cover type within each of these 250-m pixels [36]. The total area of the pixels selected as target cornfields was about 7.5 million ha, which accounted for $62 \%$ of the total harvested area in 2008.

\section{TSF Method}

The concept of the TSF method, which estimates specific phenological stages of corn, is briefly illustrated by using a sample MODIS WDRVI profile in Fig. 1. A multitemporal WDRVI profile representative of corn's typical growth cycle was preliminarily defined as the "shape model." Using optimum geometrical parameters, which convert the shape model to fit a targeted WDRVI profile, the dates of key developmental stages were estimated on a pixel scale. The functions and variables used in the TSF approach are explained as follows [36].

1) $f(x)$ : A smoothed WDRVI time series data set on a target pixel (black points in Fig. 1).

2) $g(x)$ : The shape model for the idealized WDRVI profile of corn (thin line in Fig. 1), which is preliminarily defined by averaging the eight years (2001 to 2008) of smoothed multitemporal WDRVI data observed over an experimental irrigated corn site at University of Nebraska—Lincoln. The spectral-temporal response from corn on an irrigated field is assumed to represent an idealized WDRVI profile because the site experienced minimal water stress over this eight-year period due to targeted water applications and other appropriate management practices (e.g., fertilizers). As a result, the time-series WDRVI signatures served as an appropriate reference data set to develop the shape model that would be used to preliminarily define the four targeted phenological stages of corn.

3) $h(x)$ : A rescaled shape model (thick line in Fig. 1) that is geometrically converted from the shape model $g(x)$ through

$h(x)=y$ scale $\times\{g(x$ scale $\times(x+$ tshift $))+0.5\}-0.5$

where $x$ scale, yscale, and tshift are scaling parameters that geometrically convert/shift the shape model in both $x$ and $y$ directions. $x$ implies the date (DOY).

4) $x_{0}$ : The preliminary defined key phenological stages on the shape model (gray-color-filled symbols in Fig. 1,

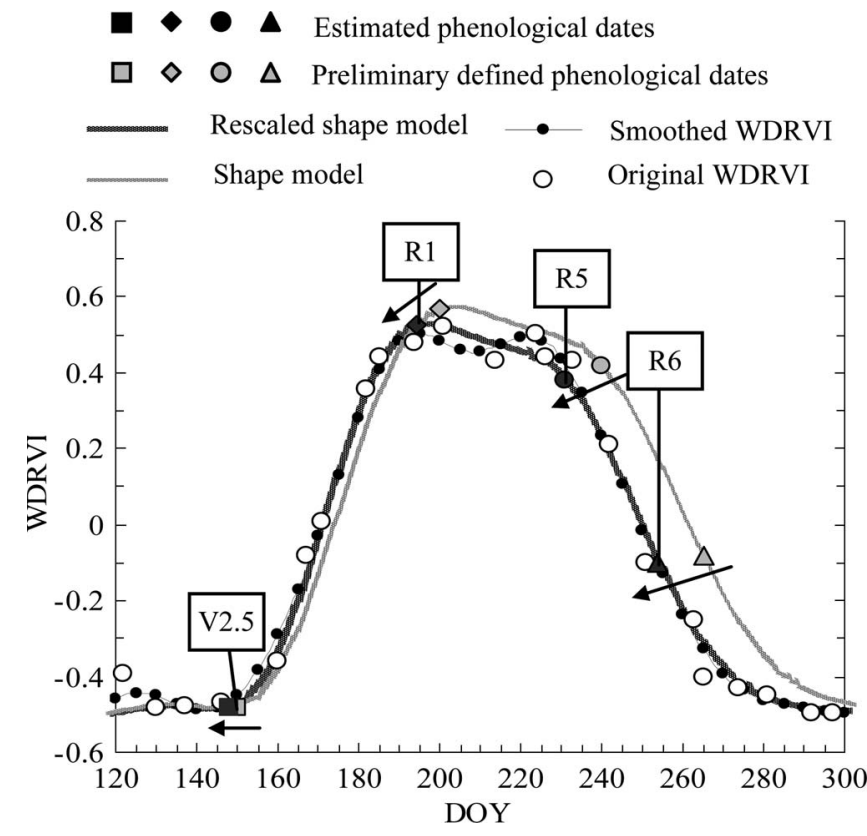

Fig. 1. TSF method is applied to detect key phenological stages of maize (V2.5, R1, R5, and R6) from the time series.

square: $x_{0: V 2.5}=\mathrm{DOY} 150$; diamond: $x_{0: R 1}=\mathrm{DOY}$ 200; circle: $x_{0: R 5}=$ DOY 240; triangle: $x_{0: R 6}=$ DOY 265). The initial values of these phenological stages $\left(x_{0: V 2.5, R 1, R 5}\right.$ and $\left.R 6\right)$ have been empirically determined on the basis of the ground-based observations [36].

5) $x_{\text {est }}$ : The estimated key phenological stages on a target pixel (black symbols in Fig. 1).

6) $\mathrm{DS}_{\mathrm{MODEL}}$ : Discrepancy score between the rescaled shape model $h(x)$ and target-smoothed WDRVI data $f(x)$

$$
D S_{\text {MODEL }}=\sqrt{\frac{1}{73} \sum_{t=5,10, \ldots 365}(f(t)-h(t))^{2}} .
$$

The TSF method calculates the dates of these key phenological stages using the following procedure. First, a waveletbased filter was used to remove non-vegetation-related noise components (e.g., residual cloud cover, bad data, or observations at extreme view angles) in time-series eight-day composite WDRVI data and derive a smoothed WDRVI time series data set calculated at five-day intervals $(f(x))$. A five-day interval was used instead of a daily time step to interpolate the time-series WDRVI data set from the eight-day composite MODIS products to minimize the computation time and harddisk space required to process the large volume of raster image data. The wavelet-based filter using a mother wavelet (coiflet, order $=4$ ) excludes noise components with a frequency higher than 80 days (a scale of four in the five-day interval input array: $2^{4} \times 5$ ). Second, the shape model $g(x)$ is geometrically converted to a rescaled shape model $h(x)$ using the three scaling parameters (xscale, yscale, and tshift) in (3). The optimum scaling parameters that enable the rescaled shape model to fit on a target-smoothed WDRVI profile $f(x)$ with the lowest $\mathrm{DS}_{\text {MODEL }}$ (4) are found by using a functional subprogram in the commercial Interactive Data Language (IDL; ITT Visual Information Solutions) programming software 
named "CONSTRAINED_MIN," which is designed for optimization analysis and is based on the Generalized Reduced Gradient Code [47]. Lastly, objective phenological stages $\left(x_{\text {est }}\right)$ are calculated using the optimum scaling parameters with the preliminary defined dates of key phenological stages $\left(x_{0}\right)$ from

$$
x_{\mathrm{est}}=x \text { scale } \times\left(x_{0}+\text { tshift }\right) .
$$

See [5] and [36] for further details about the wavelet-based filter and the TSF method.

\section{NASS-CPR}

USDA/NASS releases basic phenological information for corn and other crops in weekly CPRs that can serve as a surrogate for ground-based observations when evaluating the performance of remote-sensing-based crop phenology estimates at a regional (i.e., multistate) scale. These reports show the percent complete (area ratio) of crop fields that has either reached or completed a specific phenological stage over a given geographic area. USDA/NASS designates the timing of a phenological stage when more than $50 \%$ of plants reach the objective developmental stage on a field level. According to USDA/NASS's "Crop progress and condition survey and estimating procedures," the crop progress and condition surveys are based on questionnaires returned weekly from more than 5000 reporters, who conduct visual observations of farms and frequently contact farmers. The corn phenological stages are defined as follows: "Emerged: as soon as the plants are visible; Silking: the emergence of silklike strands from the end of ears; Dough: normally half of the kernels are showing dent with some thick or doughlike substance in all kernels; Dent: occurs when all kernels are fully dented and the ear is firm and solid and there is no milk present in most kernels; and Mature: plant is considered safe from frost and corn is about ready to be harvested with shucks opening and no green foliage present" (Definitions from USDA/NASS website available at http://www.nass.usda.gov/ Charts_and_Maps/Crop_Progress_\&_Condition/). The geographic reporting unit for the NASS-CPR varies by state. Some states, including Indiana, report the crop progress data at the state level while other states report the ASD-level data. For this research, ASD-level crop progress data were available for several study years in Illinois (2001 to 2008) and Iowa (2006 to 2008).

The weekly values of the percent complete reported in the NASS-CPR were temporally interpolated to a daily basis in order to estimate the date when each phenological stage reached specific thresholds $(5 \%, 25 \%, 50 \%, 75 \%$, and $95 \%)$ at the ASD or state level. The accuracy of the TSF method for estimating the corn phenological stage was quantitatively evaluated at the ASD level for Illinois and Iowa. The coefficient of variation $(\mathrm{CV})$, the root mean squared error (rmse), and determination coefficient $\left(R^{2}\right)$ were used as criterion for accuracy assessment.

The rmse and $\mathrm{CV}$ were calculated by the following:

$$
\begin{aligned}
\text { rmse } & =\sqrt{\frac{1}{N} \sum_{i=1,2, \ldots N}\left(y_{i}-x_{i}+\text { bias }\right)^{2}} \\
C V & =\frac{r m s e}{\bar{x}} \times 100
\end{aligned}
$$

where $x_{i}$ is the date of NASS-CPR-derived statistics when percent complete of target phenological stage reached $50 \%$ at an ASD level, $y_{i}$ is the date of MODIS-derived estimates, $N$ is the number of estimations $(y)$ compared with statistical data $(x)$, and bias is the bias-correction value. When assessing the emerged stage, we assigned the bias-correction value ( -10 days) to bias for filling the time lag caused by the different definitions between the NASS-CPR-derived emerged stage and the MODIS-estimated early vegetation stage (V2.5). For the other phenological stages of silking stage (R1), dent stage (R5), and mature stage (R6), we assigned zero to bias.

The Nash-Sutcliffe (NS) model efficiency coefficient [48], which is often used for assessing the predictive power of hydrological models, is a suitable index for quantifying the degree of coincidence between two time-series profiles. The dynamic range of NS is from minus infinity to one. If the NS is closer to one here, the temporal profile the MODIS-derived estimations is in excellent agreement with that of the NASSCPR-derived statistics. The NS was defined as follows:

$$
N S=1-\frac{\sum(p(t)-q(t+b i a s))^{2}}{\sum(p(t)-\bar{q})^{2}}
$$

where $t$ is the date when the statistical values of NASS-CPR were collected, $p(t)$ is the percent complete of a phenological stage reported in the NASS-CPR at the date $t, q(t)$ is the percent complete of a phenological stage derived from the MODIS estimates on an ASD level at the date given by $t+$ bias, and bias is the bias-correction value. As for the silking stage only of Iowa, we assessed the estimation accuracy in two different ways: 1) with the bias correction (bias $=+5$ days) and 2) without the bias correction (bias $=0$ ). On the other cases, we assigned zero to bias.

The NASS-CPR-derived statistics on a state level were used only in visual evaluation of the spatiotemporal distribution of the MODIS-estimated silking (R1) dates for missing values of ASD-level statistics in Iowa and Indiana.

\section{RESUlTS AND Discussion}

\section{A. Validation of the TSF Method for Estimating Key Phenological Stages of Corn on an ASD Level}

A comparison of the key phenological stages obtained from MODIS WDRVI and those derived from the NASS-CPR on an ASD level for Iowa and Illinois is shown in Fig. 2. Table I shows the performance of the TSF method as compared with the NASS-CPR data. The MODIS-estimated dates of the silking, dent, and mature stages were highly correlated with the NASSCPR-derived statistics in both Iowa and Indiana. The dates for each stage were generally estimated within \pm 10 days of the NASS-CPR statistics. Because of the difference in definition between the MODIS-derived early vegetative stage (V2.5, i.e., second or third leaf on corn plant formed) and the emerged stage (i.e., as soon as the plants are visible) reported by the NASS-CPR, the time lag (bias error) between them should be 


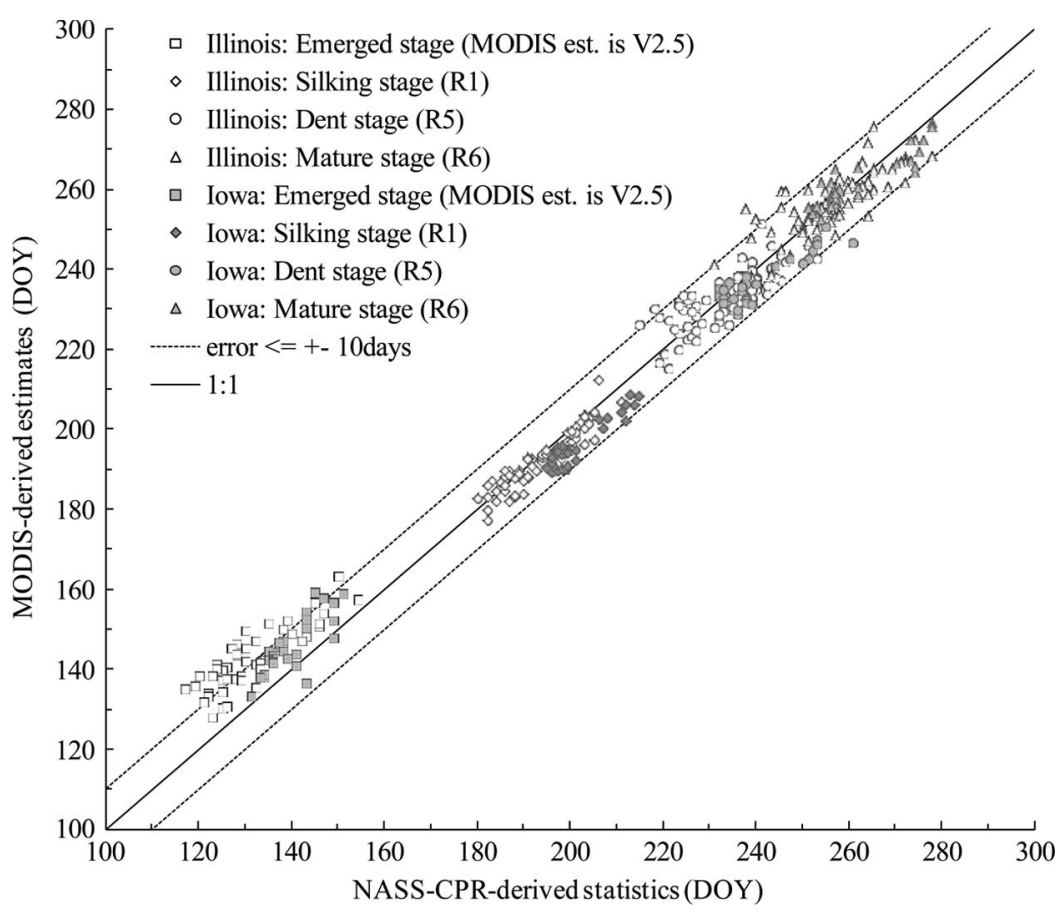

Fig. 2. Comparison of key phenological stages between the MODIS-derived estimation and the NASS-CPR.

TABLE I

Accuracy Assessment of the MOdis-Estimated Phenological Stages Against the ASD-LeVel Statistical Data IN NASS CROP Progress Reports

\begin{tabular}{|c|c|c|c|c|c|c|c|c|c|c|c|c|c|}
\hline & & & Iow & & & & Illine & & & & Tot & & \\
\hline $\begin{array}{c}\text { phenological stage } \\
\text { (MODIS est.) }\end{array}$ & $\begin{array}{c}\text { bias } \\
\text { correction }\end{array}$ & $\mathrm{R}^{2}$ & $\begin{array}{l}\text { RMSE } \\
\text { (days) }\end{array}$ & $\mathrm{CV}(\%)$ & $\mathrm{n}$ & $\mathrm{R}^{2}$ & $\begin{array}{l}\text { RMSE } \\
\text { (days) }\end{array}$ & $\mathrm{CV}(\%)$ & $\mathrm{n}$ & $\mathrm{R}^{2}$ & $\begin{array}{l}\text { RMSE } \\
\text { (days) }\end{array}$ & $\mathrm{CV}(\%)$ & $\mathrm{n}$ \\
\hline emergence (V2.5) & -10 days & 0.62 & 5.6 & 3.97 & 27 & 0.69 & 4.7 & 3.60 & 54 & 0.66 & 5.0 & 3.74 & 81 \\
\hline silking stage (R1) & - & 0.89 & 5.9 & 2.94 & 27 & 0.85 & 3.1 & 1.59 & 72 & 0.84 & 4.1 & 2.07 & 99 \\
\hline dent stage (R5) & - & 0.79 & 5.4 & 2.24 & 27 & 0.62 & 5.2 & 2.23 & 72 & 0.69 & 5.3 & 2.23 & 99 \\
\hline mature stage (R6) & - & 0.80 & 4.3 & 1.62 & 27 & 0.62 & 5.9 & 2.29 & 72 & 0.69 & 5.5 & 2.12 & 99 \\
\hline
\end{tabular}

$*_{\mathrm{n}}$ is number of the comparison data

considered when assessing the estimation accuracy. According to [49], a new leaf on a young corn plant forms approximately every four days. If this rule is applicable to the corn growth in Iowa and Illinois, the approximate ten-day difference observed between the MODIS-estimated dates of early vegetative stage (V2.5) and the NASS-CPR-derived dates of emerged stage (Fig. 2) is within the expected time lag between the two different stages.

The performance of the TSF method for estimating the corn phenological stages in this study was similar to that observed in the previous study [36]. The estimation accuracy for the silking stage in this study ( $r m s e=4.1$ days, $R^{2}=0.84$, and $n=99$ ) was higher than those of the other phenological stages at the ASD level, as well as of the results from the previous eastern Nebraska study for 2001-2002 ( $r m s e=1.6$ days, $R^{2}=0.78$, and $n=6$ ) [36]. The possible reason why the estimation accuracy for the silking stage in the previous study was higher than that in this study was that most cornfields in Iowa and Illinois are rain-fed fields; Nebraska has a higher percentage area of irrigated cornfields (61\% in 2008 [37]). The previous study suggested that the rmse of silking stage estimation for irrigated

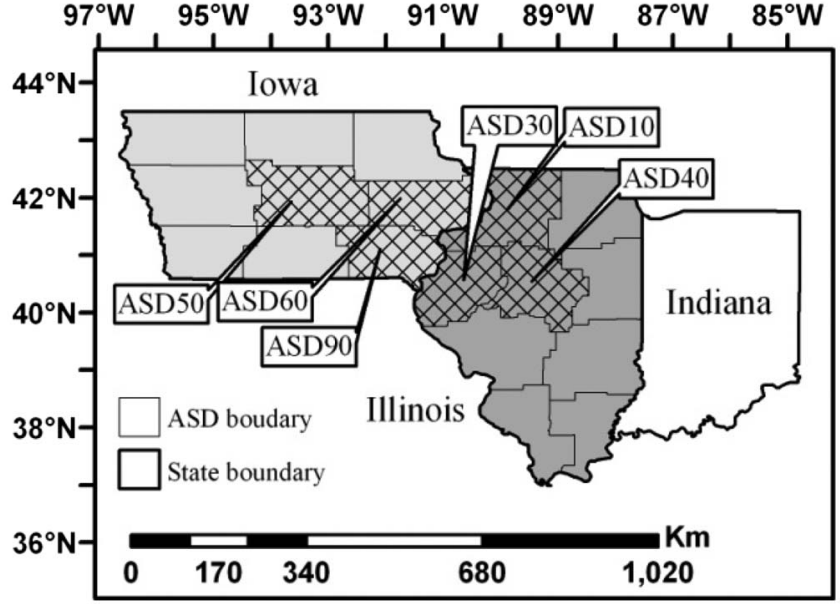

Fig. 3. Study-area location map with administrative boundaries of states and ASDs.

fields (rmse ranged from 0.7 to 2.4 days) was consistently lower than that for rain-fed fields $(r m s e=4.1$ days) [36]. It was also confirmed that the TSF method can estimate the other 

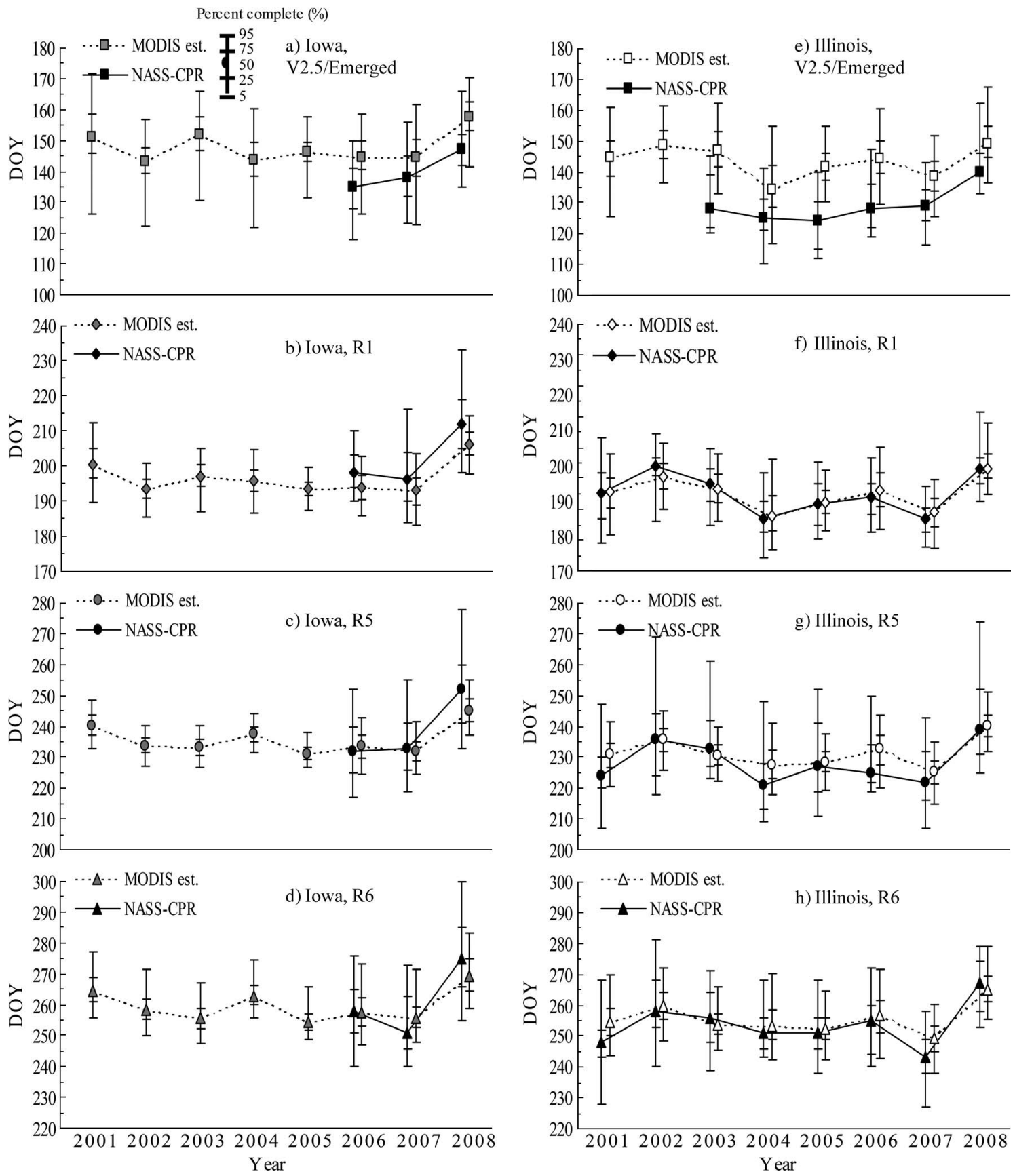

Fig. 4. Comparison of yearly changes in key phenological stages between (gray/white triangle) the MODIS-derived estimation and (black triangle) the NASSCPR on the two districts (ASD50 of Iowa and ASD40 of Illinois). (A, E) MODIS-derived V2.5 stage or the NASS-derived emerged stage. (B, F) Silking (R1) stage. (C, G) Dent (R5) stage. (D, I) Mature (R6) stage.

phenological stages with reasonable accuracy (rmse ranged from 5.0 to 5.5 days and $R^{2}$ ranged from 0.66 to 0.69 ), which was similar to the results from the pixel-scale evaluation conducted in the previous Nebraska study $(\mathrm{rmse}=3.7-7.0$ days and $R^{2}=0.39-0.81$ ) [36]. According to the results of $\mathrm{CV}$ (Table I), the estimation accuracy for early vegetative stage (V2.5) was not extremely high (CV ranged from $3.6 \%$ to $4.0 \%$ ), but tended to be lower than those for the other stages (CVs of silking, dent, and mature stages ranged from $1.6 \%$ to $3.0 \%$ ). The weak VI signal of the early vegetative stage due to low vegetation fraction may result in slightly higher CVs than those of other phenological stages.

\section{B. Comparison of Yearly Changes of the Key Phenological Stages Between the MODIS Estimates and the NASS-CPR Statistics in Iowa and Illinois}

Fig. 4 shows the yearly changes of the key phenological stages derived from the MODIS and the NASS-CPR for two districts called ASD50 in Iowa and ASD40 in Illinois (Fig. 3). The two districts were selected because they are located in the center of each state and were appropriate to represent characteristic yearly changes of the target phenological stages in both states. The yearly changes in MODIS-derived estimates, particularly for the silking and mature stages, were consistent with those dates in the NASS-CPR statistics over the eight-year 

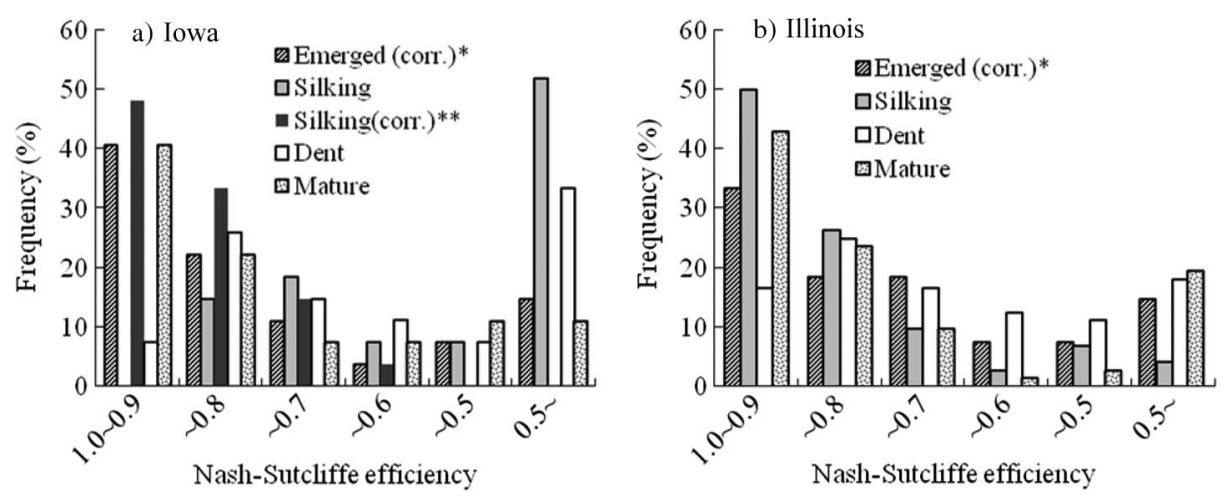

Fig. 5. Histogram of NS efficiency when comparing weekly percent complete of key phenological stages between the NASS-derived statistics and the MODISderived estimates on an ASD level in (a) Iowa and (b) Illinois. ${ }^{*}$ The bias correction ( -10 days) was conducted. ${ }^{* *}$ The bias correction $(+5$ days) was conducted only for silking stage in Iowa.

period. The percentage of crop completing each phenological stage is expressed as the accumulated area ratio (i.e., completed area divided by total planted area of corn) at the ASD level, which corresponds to error bars in Fig. 4. There are some differences in the observed range of percent complete (from 5\% to $95 \%$ ) between the MODIS-derived estimates and the NASSCPR statistics, depending on the phenological stage. The results of the NS efficiency (Fig. 5) showed that the MODIS-derived estimates corresponded well with the NASS-derived statistics in terms of time-series variation, except the silking stage of Iowa and the dent stages of both states. The percentages of samples achieving high NS values $(N S=>0.7)$ in Illinois were $70.4 \%$ $(n=38)$ for emerged stage, $86.1 \%(n=62)$ for silking stage, $58.3 \%(n=42)$ for dent stage, and $76.4 \%(n=55)$ for mature stage while those in Iowa were $74.1 \%(n=20)$ for emerged stage, 33.3\% $(n=9)$ for silking stage (without the bias correction), $48.1 \%$ ( $n=13)$ for dent stage, and $70.4 \%(n=19)$ for mature stage. When the bias correction was not applied for the silking stage in Iowa, the histogram distribution of NS for the silking stage (Fig. 5(a), gray bar) was extremely skewed toward lower categories in comparison with those in Illinois (Fig. 5(b), gray bar). On the basis of the NS histogram, the estimation accuracy for the silking stage in Iowa was considerably lower even though $R^{2}(0.89)$ and CV (2.94\%) were not much lower than those of the other stages (Table I). This suggested that a bias error was included in the NASS-CPR data. According to Fig. 2 (gray diamonds) and Fig. 4(b) (black diamonds), the NASS-derived silking stages were obviously later than the MODIS-derived estimates in Iowa, which were different from those in Illinois. When we assigned the bias-correction value ( +5 days), which was empirically determined in reference to Fig. 2, to (8) in order to investigate the effect of the bias correction on the NS value, the NS-based estimation accuracy of the MODIS-derived silking stage in Iowa was drastically improved by the bias correction $(+5$ days). The percentage of samples achieving the high NS value $(N S=>0.7)$ for the silking stage in Iowa was increased from $33.3 \%(n=9$, without the bias correction) to $96.3 \%$ ( $n=26$, with the bias correction of +5 days). This implied the possibility that the statistical value of the silking stage reported by NASS-CPR for Iowa included some bias component. We could not figure out what is behind this bias error observed only in Iowa. As will be discussed in detail in the next section, this apparent bias is illustrated by the sharp contrast and lack of a gradual spatial gradation across the state border between Iowa and Illinois in the ASD-level silking-stage maps derived from the NASS-CPR statistics [Fig. 6(v)-(x)].

The results confirmed that the TSF method using the MODIS WDRVI data was very effective for estimating the regionaverage dates of key phenological stages in terms of interannual variations. However, as can be expected from the fact that the NS value was not always high for all samples, the TSF method has the potential to overlook fields where a specific phenological stage was much earlier or later than the region average. Taking into consideration the fact that the progression rate of reproductive stages depends on environmental factors including temperature, soil water availability, available soil nutrients, and hybrid maturity differences [49], it should be noted that the temporal profile of WDRVI reflects growth and senescence rates of green vegetation, but does not have direct connection with the degrees of kernel development covered by husks below vegetative canopy.

\section{Spatial Comparison of the Dates of Silking Stage Between the MODIS-Derived Estimates and the NASS-CPR-Derived Statistics}

Heat and drought stress between the late vegetative growth stage (V10-V15) and the dent stage (R5) can cause a decrease in the final yield of corn [50]. In particular, the pollination and fertilization period around the silking stage (R1) is the most sensitive crop developmental stage to drought stress, because drought conditions cause poor or incomplete pollination, which results in a high percentage of sterility. Thus, the MODISderived estimates, which can rearrange gridded meteorological data (reanalysis data) in chronological order based on crop phenology, would enable us to assess how much the spatiotemporal correspondence between specific crop developmental stage variations and abnormal weather conditions (e.g., drought) impacts final crop yields across large geographic areas. Fig. 6 shows a comparison between the MODIS-derived county-level estimates of the silking stage and the corresponding ASD-level statistics in the NASS-CPRs (defined as 50\% of corn in the ASD having completed the silking stage) from 2001 to 2008. 


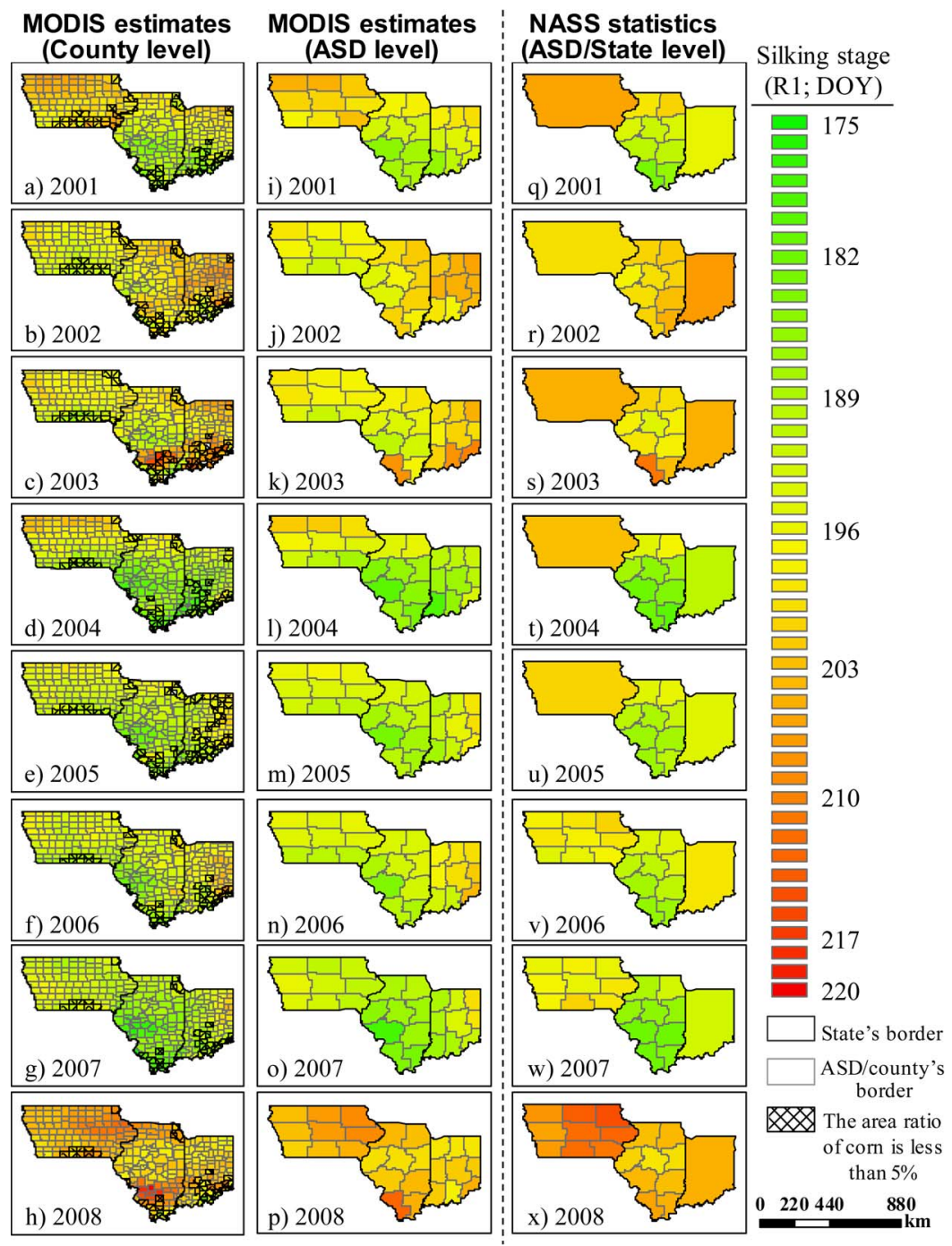

Fig. 6. Spatial comparison of MODIS-derived silking stage on $(\mathrm{a}-\mathrm{h})$ a county level or $(\mathrm{i}-\mathrm{p})$ an ASD level and NASS-derived statistics on ( $\mathrm{q}-\mathrm{x})$ an ASD level in Iowa, Illinois, and Indiana from 2006 to 2008.

The counties where the area ratio of the target corn pixels to the total area of county is less than $5 \%$ were not considered in this analysis and shaded by a mesh pattern in Fig. 6(a)-(h). Although the MODIS-derived estimates could be scalable from a pixel level to any administrative level (e.g., county, ASD, or state level) on the map, there was possibility that unreliable results were acquired for counties with a small percentage cornfield, for example, some counties in the southern part of Indiana in 2008 [Fig. 6(h)].

As briefly described in Section IV-B, a visual assessment of the NASS-CPR-derived phenology maps showed a sharp contrast along the Iowa-Illinois border, suggesting that a bias in the ASD-level reporting on the silking stage exists between these two states. This contrast is particularly apparent from 2006 to 2008 [Fig. 6(v)-(x)]. On average, the NASS-CPRderived statistics for ASD60 and ASD90 in Iowa were about nine days later than those for ASD10 and ASD30 in Illinois from 2006 to 2008. In comparison, the MODIS-estimated silking dates show a natural gradation and spatial continuity across the Iowa-Illinois state border on both a county level [Fig. 6(a)-(h)] and an ASD level [Fig. 6(i)-(p)]. Excluding the apparent several-day bias observed in Iowa, the general spatial features of the MODIS-estimated silking date maps had a high level of agreement with those of the NASS-CPRderived statistics at the ASD level over Illinois for most years [Fig. 6(i)-(x)]. In addition, the MODIS-derived silking stage at the county and ASD levels was in excellent spatial agreement with the NASS-CPR-derived statistics at the state level over Iowa and Indiana (Fig. 6). The MODIS-estimated silking dates in Illinois were earlier than those in Indiana from 2005 to 2007 [Fig. 6(m)-(p)], which were also reported and observed in the NASS-CPR silking date maps [Fig. 6(u)-(x)]. In terms of the yearly change, the MODIS-estimated silking dates in 2008 were much later than those in the previous four years (2004-2007), which was also reflected in the NASS-CPR data. The later silking dates were attributed to a delay in corn planting due to higher precipitation, cool temperatures, and wet soils during the spring of 2008 [51], [52]. This suggested that the TSF method provides an effective means to assess intraregional and interannual variations in corn phenology.

We speculated that the following three factors resulted in the high estimation performance of the TSF method for key 
phenological stages in this study area. First, the field scale of cropland $(160$ acres $\cong 805 \mathrm{~m} \times 805 \mathrm{~m})$ in the U.S. is typically larger than the 250-m spatial resolution of MODIS, because land allocation was conducted in accordance with the Homestead Act of 1862 [53]. Second, genetically modified herbicide-resistant crop varieties prevent extensive weed growth within fields, resulting in less mixed-pixel effect of weeds on the MODIS WDRVI profile that have been observed earlier in the growing season and can affect the identification of early-stage crop growth stages. Third, detailed land-use maps (NASS-CDL) are available for most crop-intensive states to select the specific MODIS pixels primarily covered by corn $(\geq 75 \%)$. Although the estimation accuracy of the TSF method may be affected by field scale, weed management, and quality of available ancillary information related to land use, we believe that the TSF method is useful for revealing the spatiotemporal pattern of corn phenology in different regions or countries.

\section{CONCLuSiON}

In this paper, we have tested the performance of a new technique, called as the TSF method [36], to estimate four phenological stages of corn on a multistate scale across the U.S. Corn Belt and to investigate the spatiotemporal characteristics of the silking stage at the regional scale. General crop phenology information published in the NASS-CPR, which represents the best available data on annual crop development across the U.S., was used to verify the TSF method's performance across Illinois, Indiana, and Iowa over an eight-year period (2001-2008). The results confirmed that the TSF method without any modification of parameters could accurately estimate the early vegetative stage (V2.5), the silking stage (R1), the dent stage (R5), and the mature stage (R6) on an ASD level with rmse ranging from 4.1 to 5.5 days and $R^{2}$ ranging from 0.66 to 0.84 . According to the validation results, which were based on the NS efficiency statistics coupled with the bias correction, the estimation accuracy for the dent stage was the lowest of the four developmental stages in terms of its correspondence with a time series of percent complete information for that specific stage reported by USDA/NASS at the ASD level. In addition, it was suggested that there were obvious bias errors (ca. +5 days) between the NASS-derived statistics of silking stage and the MODIS-derived estimates only in Iowa for unknown reasons. However, the spatial patterns of the estimated silking dates at the ASD levels had a high level of agreement with those of the NASS-CPR-derived statistics particularly for Illinois from 2001 to 2008.

A primary advantage of the TSF method is the identification of the crop developmental stages at the 250-m MODIS pixel level, which provides detailed patterns of spatiotemporal crop phenology variations that can be scaled up from the initial 250-m crop phenology maps across a range of administrative geographic units including county, ASD, state, and multistate regions. The potential applicability of the TSF method is to provide local-scale information about corn development stages across large geographic areas in multiple years, which enables us to interpret the macroscale relationship between county-level corn production and extreme climate conditions (e.g., drought, flooding, or early season freeze) on the basis of the key crop developmental stages. In this regard, we concluded that the TSF method using time-series MODIS WDRVI data has an advantage over the NASS-CPR for revealing the spatiotemporal patterns of corn phenology in terms of ability to resolve the detailed spatial pattern of county to subcounty condition, cost and time efficiency, and objective procedure without subjective field observation.

\section{ACKNOWLEDGMENT}

The authors would like to thank the National Drought Mitigation Center, University of Nebraska-Lincoln, for allowing the use of facilities and equipment, Dr. D. A. Wilhite, Dr. S. Swain, Dr. M. J. Hayes, Dr. T. Tadesse, Dr. T. Akenbauer, Dr. S. B. Verma, Dr. A. E. Suyker, T. T. Schimelfenig, and D. A. Wood of the School of Natural Resources, University of NebraskaLincoln for their valuable comments and research support, and the two anonymous reviewers for their valuable comments and suggestions.

\section{REFERENCES}

[1] B. C. Reed, J. F. Brown, D. Vanderzee, T. R. Loveland, J. W. Merchant, and D. O. Ohlen, "Measuring phenological variability from satellite imagery," J. Vegetation Sci., vol. 5, no. 5, pp. 703-714, Nov. 1994.

[2] M. A. White, P. E. Thornton, and S. W. Running, "A continental phenology model for monitoring vegetation responses to interannual climatic variability," Global Biogeochem. Cycles, vol. 11, no. 2, pp. 217-234, Jun. 1997.

[3] M. D. Schwartz and B. C. Reed, "Surface phenology and satellite sensorderived onset of greenness: An initial comparison," Int. J. Remote Sens., vol. 20, no. 17, pp. 3451-3457, Nov. 1999.

[4] B. D. Wardlow, J. H. Kastens, and S. L. Egbert, "Using USDA crop progress data for the evaluation of greenup onset date calculated from MODIS 250-meter data," Photogramm. Eng. Remote Sens., vol. 72, no. 11, pp. 1225-1234, Nov. 2006.

[5] T. Sakamoto, M. Yokozawa, H. Toritani, M. Shibayama, N. Ishitsuka, and H. Ohno, "A crop phenology detection method using time-series MODIS data," Remote Sens. Environ., vol. 96, no. 3/4, pp. 366-374, Jun. 2005.

[6] K. M. de Beurs and G. M. Henebry, "Land surface phenology, climatic variation, and institutional change: Analyzing agricultural land cover change in Kazakhstan," Remote Sens. Environ., vol. 89, no. 4, pp. 497509, Feb. 2004

[7] R. Suzuki, T. Nomaki, and T. Yasunari, "West-east contrast of phenology and climate in northern Asia revealed using a remotely sensed vegetation index," Int. J. Biometeorol., vol. 47, no. 3, pp. 126-138, May 2003.

[8] X. Y. Zhang, M. A. Friedl, C. B. Schaaf, A. H. Strahler, J. C. F. Hodges, F. Gao, B. C. Reed, and A. Huete, "Monitoring vegetation phenology using MODIS," Remote Sens. Environ., vol. 84, no. 3, pp. 471-475, Mar. 2003.

[9] A. R. Huete, K. Didan, Y. E. Shimabukuro, P. Ratana, S. R. Saleska, L. R. Hutyra, W. Yang, R. R. Nemani, and R. Myneni, "Amazon rainforests green-up with sunlight in dry season," Geophys. Res. Lett., vol. 33, no. 6, p. L06 405, Mar. 2006.

[10] H. Carrao, P. Goncalves, and M. Caetano, "A nonlinear harmonic model for fitting satellite image time series: Analysis and prediction of land cover dynamics," IEEE Trans. Geosci. Remote Sens., vol. 48, no. 4, pp. 19191930, Apr. 2010.

[11] R. R. Colditz, C. Conrad, T. Wehrmann, M. Schmidt, and S. Dech, "TiSeG: A flexible software tool for time-series generation of MODIS data utilizing the quality assessment science data set," IEEE Trans. Geosci. Remote Sens., vol. 46, no. 10, pp. 3296-3308, Oct. 2008.

[12] J. F. Hermance, R. W. Jacob, B. A. Bradley, and J. F. Mustard, "Extracting phenological signals from multiyear AVHRR NDVI time series: Framework for applying high-order annual splines with roughness damping," IEEE Trans. Geosci. Remote Sens., vol. 45, no. 10, pp. 3264-3276, Oct. 2007.

[13] M. A. White and R. R. Nemani, "Real-time monitoring and short-term forecasting of land surface phenology," Remote Sens. Environ., vol. 104, no. 1, pp. 43-49, Sep. 2006.

[14] J. P. Jenkins, B. H. Braswell, S. E. Frolking, and J. D. Aber, "Detecting and predicting spatial and interannual patterns of temperate forest spring- 
time phenology in the eastern US," Geophys. Res. Lett., vol. 29, no. 24, pp. 54-1-54-4, Dec. 2002.

[15] F. Maignan, F. M. Breon, C. Bacour, J. Demarty, and A. Poirson, "Interannual vegetation phenology estimates from global AVHRR measurements-Comparison with in situ data and applications," Remote Sens. Environ., vol. 112, no. 2, pp. 496-505, Feb. 2008.

[16] M. Boschetti, D. Stroppiana, P. A. Brivio, and S. Bocchi, "Multi-year monitoring of rice crop phenology through time series analysis of MODIS images," Int. J. Remote Sens., vol. 30, no. 18, pp. 4643-4662, 2009.

[17] X. Y. Zhang, M. A. Friedl, and C. B. Schaaf, "Global vegetation phenology from Moderate Resolution Imaging Spectroradiometer (MODIS): Evaluation of global patterns and comparison with in situ measurements," J. Geophys. Res.-Biogeosciences, vol. 111, no. G4, p. G04 017, Dec. 2006.

[18] P. S. A. Beck, C. Atzberger, K. A. Hogda, B. Johansen, and A. K. Skidmore, "Improved monitoring of vegetation dynamics at very high latitudes: A new method using MODIS NDVI," Remote Sens. Environ., vol. 100, no. 3, pp. 321-334, Feb. 2006

[19] B. Duchemin, J. Goubier, and G. Courrier, "Monitoring phenological key stages and cycle duration of temperate deciduous forest ecosystems with NOAA/AVHRR data," Remote Sens. Environ., vol. 67, no. 1, pp. 68-82, Jan. 1999.

[20] M. D. Schwartz, B. C. Reed, and M. A. White, "Assessing satellite-derived start-of-season measures in the conterminous USA," Int. J. Climatol., vol. 22 , no. 14 , pp. 1793-1805, Nov. 2002.

[21] M. J. Hill and G. E. Donald, "Estimating spatio-temporal patterns of agricultural productivity in fragmented landscapes using AVHRR NDVI time series," Remote Sens. Environ., vol. 84, no. 3, pp. 367-384, Mar. 2003.

[22] K. P. Gallo and T. K. Flesch, "Large-area crop monitoring with the NOAA AVHRR: Estimating the silking stage of corn development," Remote Sens. Environ., vol. 27, no. 1, pp. 73-80, Jan. 1989.

[23] T. Sakamoto, N. Van Nguyen, H. Ohno, N. Ishitsuka, and M. Yokozawa, "Spatio-temporal distribution of rice phenology and cropping systems in the Mekong Delta with special reference to the seasonal water flow of the Mekong and Bassac rivers," Remote Sens. Environ., vol. 100, no. 1, pp. 1-16, Jan. 2006.

[24] X. M. Xiao, S. Hagen, Q. Y. Zhang, M. Keller, and B. Moore, III, "Detecting leaf phenology of seasonally moist tropical forests in South America with multi-temporal MODIS images," Remote Sens. Environ., vol. 103, no. 4, pp. 465-473, Aug. 2006.

[25] M. E. Brown and K. M. de Beurs, "Evaluation of multi-sensor semiarid crop season parameters based on NDVI and rainfall," Remote Sens. Environ., vol. 112, no. 5, pp. 2261-2271, May 2008.

[26] S. Y. Kang, S. W. Running, J. H. Lim, M. Zhao, C.-R. Park, and R. Loehman, "A regional phenology model for detecting onset of greenness in temperate mixed forests, Korea: An application of MODIS leaf area index," Remote Sens. Environ., vol. 86, no. 2, pp. 232-242, Jul. 2003.

[27] B. D. Wardlow and S. L. Egbert, "Large-area crop mapping using timeseries MODIS $250 \mathrm{~m}$ NDVI data: An assessment for the US Central Great Plains," Remote Sens. Environ., vol. 112, no. 3, pp. 1096-1116, Mar. 2008.

[28] T. Sakamoto, V. P. Cao, A. Kotera, K. Nguyen, and M. Yokozawa, "Detection of yearly change in farming systems in the Vietnamese Mekong Delta from MODIS time-series imagery," JARQ-Jpn. Agric. Res. Quart., vol. 43, no. 3, pp. 173-185, Jul. 2009.

[29] G. L. Galford, J. F. Mustard, J. Melillo, A. Gendrin, C. C. Cerri, and C. E. P. Cerri, "Wavelet analysis of MODIS time series to detect expansion and intensification of row-crop agriculture in Brazil," Remote Sens. Environ., vol. 112, no. 2, pp. 576-587, Feb. 2008.

[30] J. C. Brown, W. E. Jepson, J. H. Kastens, B. D. Wardlow, J. M. Lomas, and K. P. Price, "Multitemporal, moderate-spatial-resolution remote sensing of modern agricultural production and land modification in the Brazilian Amazon," GIScience Remote Sens., vol. 44, no. 2, pp. 117-148, Apr.-Jun. 2007.

[31] X. Xiao, S. Boles, S. Frolking, C. Li, J. Y. Babu, W. Salas, and B. Moore, III, "Mapping paddy rice agriculture in South and Southeast Asia using multi-temporal MODIS images," Remote Sens. Environ., vol. 100, no. 1, pp. $95-113$, Jan. 2006.

[32] B. D. Wardlow, S. L. Egbert, and J. H. Kastens, "Analysis of time-series MODIS $250 \mathrm{~m}$ vegetation index data for crop classification in the US Central Great Plains," Remote Sens. Environ., vol. 108, no. 3, pp. 290310, Jun. 2007.

[33] T. Sakamoto, N. Van Nguyen, A. Kotera, H. Ohno, N. Ishitsuka, and M. Yokozawa, "Detecting temporal changes in the extent of annual flooding within the Cambodia and the Vietnamese Mekong Delta from MODIS time-series imagery," Remote Sens. Environ., vol. 109, no. 3, pp. 295-313, Aug. 2007.

[34] H. M. Yan, Y. L. Fu, X. M. Xiao, H. Q. Huang, H. He, and L. Ediger, "Modeling gross primary productivity for winter wheat-maize double cropping system using MODIS time series and $\mathrm{CO} 2$ eddy flux tower data," Agric. Ecosyst. Environ., vol. 129, no. 4, pp. 391-400, Feb. 2009.

[35] T. Sakamoto, C. Van Phung, A. Kotera, K. D. Nguyen, and M. Yokozawa, "Analysis of rapid expansion of inland aquaculture and triple ricecropping areas in a coastal area of the Vietnamese Mekong Delta using MODIS time-series imagery," Landscape Urban Plan., vol. 92, no. 1, pp. 34-46, Aug. 2009.

[36] T. Sakamoto, B. D. Wardlow, A. A. Gitelson, S. B. Verma, A. E. Suyker, and T. J. Arkebauer, "A two-step filtering approach for detecting maize and soybean phenology with time-series MODIS data," Remote Sens. Environ., vol. 114, no. 10, pp. 2146-2159, Oct. 2010.

[37] NASS, National Agricultural Statistics Service (NASS), Feb. 7, 2010 [Online]. Available: http://www.nass.usda.gov/

[38] E. F. Vermote, N. Z. El Saleous, and C. O. Justice, "Atmospheric correction of MODIS data in the visible to middle infrared: First results," Remote Sens. Environ., vol. 83, no. 1/2, pp. 97-111, Nov. 2002.

[39] A. Huete, K. Didan, T. Miura, E. P. Rodriguez, X. Gao, and L. G. Ferreira, "Overview of the radiometric and biophysical performance of the MODIS vegetation indices," Remote Sens. Environ., vol. 83, no. 1/2, pp. 195-213, Nov. 2002.

[40] P. S. Thenkabail, M. Schull, and H. Turral, "Ganges and Indus river basin land use/land cover (LULC) and irrigated area mapping using continuous streams of MODIS data," Remote Sens. Environ., vol. 95, no. 3, pp. 317 341, Apr. 2005.

[41] J. Rouse, "Monitoring vegetation systems in the Great Plains with ERTS," in Proc. 3rd ERTS Symp., 1973, pp. 309-317.

[42] A. A. Gitelson, "Wide dynamic range vegetation index for remote quantification of biophysical characteristics of vegetation," J. Plant Physiol., vol. 161, no. 2, pp. 165-173, Feb. 2004.

[43] A. A. Gitelson, B. D. Wardlow, G. P. Keydan, and B. Leavitt, "An evaluation of MODIS 250-m data for green LAI estimation in crops," Geophys. Res. Lett., vol. 34, no. 20, p. L20 403, Oct. 2007.

[44] A. Vina, G. M. Henebry, and A. A. Gitelson, "Satellite monitoring of vegetation dynamics: Sensitivity enhancement by the wide dynamic range vegetation index," Geophys. Res. Lett., vol. 31, no. 4, p. L04 503, Feb. 2004.

[45] A. A. Gitelson, A. Vina, J. G. Masek, S. B. Verma, and A. E. Suyker, "Synoptic monitoring of gross primary productivity of maize using Landsat data," IEEE Geosci. Remote Sens. Lett., vol. 5, no. 2, pp. 133-137, Apr. 2008.

[46] A. Vina and A. A. Gitelson, "New developments in the remote estimation of the fraction of absorbed photosynthetically active radiation in crops," Geophys. Res. Lett., vol. 32, no. 17, p. L17 403, Sep. 2005.

[47] L. S. Lasdon, A. D. Waren, A. Jain, and M. Ratner, "Design and testing of a generalized reduced gradient code for nonlinear programming," ACM Trans. Math. Softw. (TOMS), vol. 4, no. 1, pp. 34-50, Mar. 1978.

[48] J. E. Nash and J. V. Sutcliffe, "River flow forecasting through conceptual models part I-A discussion of principles," J. Hydrol., vol. 10, no. 3 , pp. 282-290, Apr. 1970.

[49] D. R. Hick, S. L. Naeve, J. M. Bennett, "The corn growers field guide for evaluating crop damage and replant options," Univ. Minnesota Printing Serv., Minneapolis, MN, 1999, pp. 44.

[50] R. C. Hall and E. K. Twidwell, Effects of Drought Stress on Corn Production. [Online]. Available: http://agbiopubs.sdstate.edu/articles/ ExEx8033.pdf

[51] R. Elmore, Is All Well That Ends Well? Iowa Corn -2008, Nov. 30, 2009. [Online]. Available: http://www.extension.iastate.edu/CropNews/2008/ 1208elmoreabendroth.htm

[52] R. L. Nielsen, More Thoughts on Late Corn Planting, Nov. 30, 2009 [Online]. Available: http://www.agry.purdue.edu/Ext/corn/news/articles. 08/delayedpltupdate-0523.html

[53] F. A. Shannon, "The homestead act and the labor surplus," Amer. Historical Rev., vol. 41, no. 4, pp. 637-651, Jul. 1936.

Toshihiro Sakamoto received the B.S. degree and the Ph.D. degree in agricultural science from Kyoto University, Kyoto, Japan, in 2001 and 2008 , respectively.

He has been with the National Institute for Agro-Environmental Sciences, Tsukuba, Japan, as a Researcher since 2002. He was also with the School of Natural Resources, University of Nebraska, Lincoln, as a visiting researcher from 2008 to 2010. His main research interests are the application of remote sensing for crop phenology monitoring, spatiotemporal assessment of vegetation growth, and flood inundation. 
Brian D. Wardlow received the B.S. degree in geography and geology from Northwest Missouri State University, Maryville, in 1994, the M.A. degree in geography from Kansas State University, Manhattan, in 1996, and the Ph.D. degree in geography from The University of Kansas, Lawrence, in 2005.

He is currently an Assistant Professor and a GIScience Program Area Leader with the National Drought Mitigation Center, University of Nebraska, Lincoln. Previous positions included NASA Earth System Science Graduate Student Research Fellow during his Ph.D. program and Remote Sensing Scientist with the U.S. Geological Survey's Earth Resources Observation and Science Center, where he worked as part of the National Land Cover Data Set team. His primary research interests are the application of remote sensing for drought monitoring, land-use/land-cover classification, vegetation phenology assessment, and estimation of biophysical vegetation characteristics.
Anatoly A. Gitelson received the M.Sc. degree in electronics and the Ph.D. degree in radio physics from The Institute of Radio Technology, Taganrog, USSR.

$\mathrm{He}$ is currently with the School of Natural Resources, University of Nebraska, Lincoln. His main research interests are in remote sensing of vegetation and water. $\mathrm{He}$ is the author of more than 130 peer-reviewed articles. 